\title{
Research on the Connotation and Implementation Path of Innovation-Driven Development Strategy
}

\author{
Lin Jiang1,2 \\ ${ }^{1}$ Yancheng Teachers University, Yancheng, China \\ ${ }^{2}$ Nanjing University of Aeronautics and Astronautics, Nanjing, China \\ Email: jiangl@yctu.edu.cn
}

How to cite this paper: Jiang, L. (2022) Research on the Connotation and Implementation Path of Innovation-Driven Development Strategy. American Journal of Industrial and Business Management, 12, 145-152.

https://doi.org/10.4236/ajibm.2022.122010

Received: January 27, 2022

Accepted: February 20, 2022

Published: February 23, 2022

Copyright (C) 2022 by author(s) and Scientific Research Publishing Inc. This work is licensed under the Creative Commons Attribution International License (CC BY 4.0).

http://creativecommons.org/licenses/by/4.0/

(c) (i) Open Access

\begin{abstract}
Innovation-driven development strategy comes from the practice of socialism with Chinese characteristics and needs to be deepened, tested and expanded continuously in practice. In order to better guide, promote, enrich and test our innovation practice, this paper decomposes and excavates the connotation of innovation-driven development strategy: innovation-driven development strategy is an important driving force and inevitable choice under the new situation in China, and it is a comprehensive and in-depth, long-term and continuous systematic project. Based on the two connotations of the innovation-driven development strategy, this paper has studied five implementation paths of the innovation-driven development strategy based on the literature analysis method: firstly, scientific and technological innovation should be the "bull's nose", secondly, innovative talents should grow healthily and there should be a "blowout" phenomenon, and thirdly, there should be a strong confidence in innovation. Third, there should be a strong confidence in innovation, fourth, we should take the path of combining independent, cooperative and asymmetric innovation, and fifth, we should let the innovation results be transformed. Through the analysis of the connotation of innovation-driven development strategy and the study of the implementation path, we can inject new vitality into the national and regional science and technology development.
\end{abstract}

\section{Keywords}

Innovation-Driven, Development Strategy, Scientific and Technological Innovation, Scientific and Technological Talents, Transformation of 
Achievements

\section{Introduction}

China's past hardship was "the road to success is like iron", while the new era has ushered in "the right path is the vicissitudes of the world", and the future will be "the long wind will break the waves". China has to take the right road, the road of rejuvenation, the road of recreating glory, the road of socialism with Chinese characteristics, while carrying forward the Chinese spirit, gathering Chinese strength, and driving development with innovation (Shi \& Li, 2021). The innovation-driven development strategy originates from the practice of socialism with Chinese characteristics and runs through all the strategies related to development, such as the strategies of developing the country through science and education and strengthening the country through talents. Development is an eternal theme, the clock of development will not wait, and innovation can drive development and solve all problems encountered in development. China's leadership collective represented by Xi Jinping attaches great importance to innovation, innovation everywhere, innovation for all. What is the innovationdriven development strategy and how to do it, we first need to break down and dig into the connotation of innovation-driven development strategy.

\section{The Connotation of Innovation-Driven Development Strategy}

\subsection{Innovation-Driven Development Strategy Is an Important Driving Force and Inevitable Choice in the New Situation of China}

Throughout the history of human development, the only way for a country or a nation to progress and be strong is to innovate in order to achieve a long-lasting victory, and innovation has always been an important force to push the country, nation and human society forward. The more firmly innovation is grasped, the earlier it is planned, the better the development will be. If you do not innovate, you will fall behind, and slow innovation is also a kind of backwardness, and you will be beaten if you fall behind. Innovation-driven is both the situation is forced, but also the inevitable choice (Li \& Zhang, 2020). China's economic development, modernization, cultural construction, people's livelihood, the overall strict governance of the Party and other developments have stepped up to a new level, but the factor drive gradually declined or even zero, a variety of uncoordinated and unsustainable factors come to the fore, and the pressure of reform has grown. Standing at a new starting point, we must reacquaint ourselves with change, seriously respond to change, proactively seek change, and not miss any opportunity for development. Innovation-driven development strategy is an inevitable choice to deepen reform comprehensively, an inevitable choice to cope 
with environmental changes, an inevitable choice to maintain high economic growth, an inevitable choice to solve various social contradictions, an inevitable choice to gain more advantages, an inevitable choice to have the right to speak actively, an inevitable choice to enhance the core competitiveness of the country, and an inevitable choice for the healthy development of socialism (Shen, 2021).

\subsection{Innovation-Driven Development Strategy Is a Comprehensive and In-Depth, Long-Term and Continuous System Engineering}

Innovation-driven development must be comprehensive. Comprehensiveness is not only about "building a moderately prosperous society, deepening reform, ruling the country by law, and ruling the Party strictly"; it is also about all-round innovation and innovation without dead ends, which should be integrated into every moment, every corner, and everything to achieve innovation for everyone and everywhere (Shen, 2021). Comprehensiveness is also reflected in cooperation, making itself in the world of global innovation network, interconnecting with people all over the world to tackle problems and challenges and progress together. Innovation-driven development must go deeper, giving full play to the government's function of formulating policy systems and creating innovation ecologies, giving full play to the market's function of evaluation and regulation, and giving full play to the social third party's function of exploring diversified wisdom services. Innovation-driven development must be persistent and sustained in the long run. Innovation is never-ending, we must carry forward the spirit of nailing, and strive to make every nail firm, stable and solid, and strive for excellence; one nail after another, accumulate, and strive to achieve results; the speed of nailing should also be fast, when others are accelerating, we not only can not slow down, but also full of energy to continue to accelerate forward. Innovation-driven development must be systematized. It must be a complete system from scientific research to the development of innovative results, to find the power source and then transformed into real productivity, and the country, and the people, and the market, and society, and the needs of science and technology fully coincide, is a synergistic system project containing the linkage of industry, academia, government and research, the linkage of upstream, midstream and downstream, and the linkage of small, medium and large enterprises.

\section{The Realization Path of Innovation-Driven Development Strategy}

I searched for "Innovation-driven development" in Web of Science, input the abstracts of the 100 most relevant papers into Gooseeker software for word separation, word selection and co-linear matching, and then input the co-linear matching matrix generated by the system into Gephi software for cluster analysis. The results are shown in Figure 1.

According to Figure 1, we can see that the development of the innovationdriven development strategy needs to be driven by five paths, including scientific 


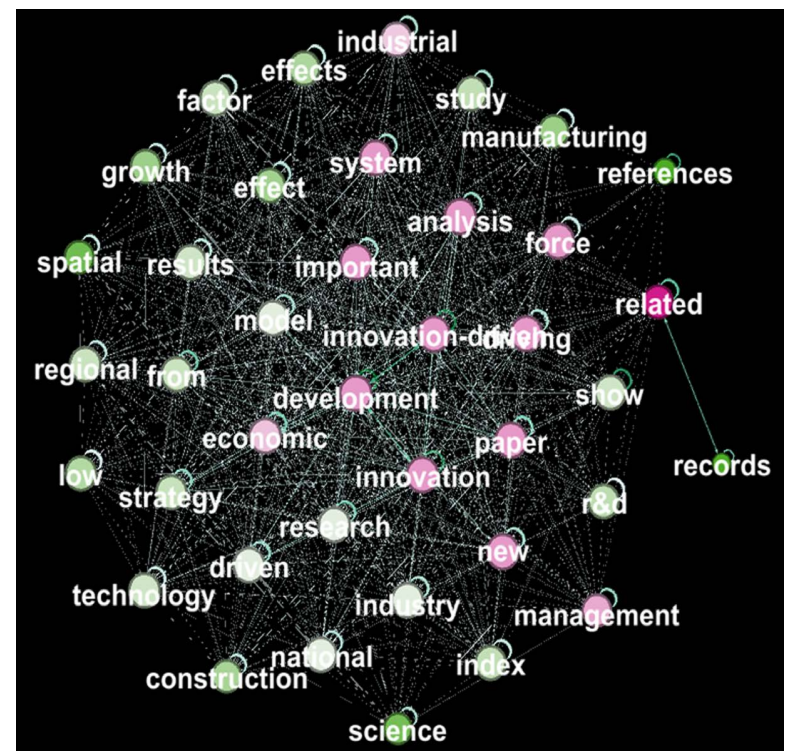

Figure 1. Keyword clustering chart of innovation-driven development path.

and technological innovation, innovative talents, innovation confidence, independent innovation and transformation of innovation results.

\subsection{The Implementation of Innovation-Driven Development Strategy to Science and Technology Innovation as the "Bull's Nose"}

Science and technology is the tool of the country, the country depends on it to be strong, the enterprise depends on it to win, and the people's life depends on it to be good. Science and technology can change the fate of a country, a nation, an enterprise and the whole people (Yin, 2021). For China to be strong and for the Chinese people to live well, there must be strong science and technology. We should enhance the sense of mission, treat science and technology innovation as an aircraft carrier, dock with the world's science and technology frontier, master the global science and technology, hold up the country's major development needs, respect the law of science and technology development, do a good job of top-level design of science and technology development, optimize the layout of science and technology development, thicken the foundation of science and technology development, form a regional center of science and technology development, enhance the science and technology and the economy, enterprises, products, markets, brands, people's livelihood, society, management

\subsection{The Implementation of Innovation-Driven Development Strategy Should Let Innovative Talents Emerge Like a "Blowout"}

"Success is achieved by talent, and career is broadened by talent." Making innovative talents healthier is a prerequisite for achieving the goal of wellbeing. Talent health includes physical, psychological, environmental and life health, but 
also includes access to health services and health protection and other all-round, full-cycle health. Innovative talents should focus on innovation while maintaining their own health of all kinds. China is a big talent country, the purpose of science and education is to let the talent like "well" emerge, "blue out of blue but better than blue", "the wave after the Yangtze River push the wave before" (Wang \& Gu, 2019). Whether innovation or development, the key depends on talents. To strengthen the construction of innovative talents and to form a pattern of people making the best use of their talents and their success, we must, firstly, recruit talents and put morality first; secondly, education-based and practical; thirdly, we must introduce talents according to the needs and combine virtue and talent; fourthly, we must strengthen the construction of party and governmental talents; fifthly, we must optimize the environment for the growth of talents; sixthly, we must use them as the basis and let go of them; sixthly, we must play the role of unity and leadership of strategic talents and leading talents; seventhly, we must conduct traditional virtues, connect personal destiny with national destiny, connect personal dreams with the Chinese dream, and "worry about the world first and be happy afterwards".

\subsection{Implementation of Innovation-Driven Development Strategy Requires Strong Innovation Confidence}

"Learning is valuable to know doubt, small doubt is small progress, big doubt is big progress." Innovation should have a strong sense of innovation, everything should know what it is more know what it is, not clear to ask, dare to question all theories, to believe that all theories and views have the space to design and improve; "to have the will to open the road in the mountains and build bridges in the rivers", to maintain the courage to innovate; to remember that "learning like a bow and arrowhead", sink down to systematically learn scientific knowledge, let diligent learning become the driving force of the voyage, let the growth of skills become the energy of the fight; to remember that "from good as ascent, from evil as a collapse", to establish oneself with virtue, to establish learning with virtue, and to be a good leader and pioneer in practicing innovation. After generations of revolutionary pioneers' hard work, China has been approaching or even catching up with the world's most advanced science and technology in many fields, changing from "running with" to "parallel" and from "parallel" to "leading". "The gap between "leading" and "leading" is still increasing. Every innovative talent should have strong innovation confidence, because our road, our theory, our system, our culture and our people give us enough reasons to be confident, and we should have enough confidence and determination to achieve greater leapsand bounds from a new starting point (Li, 2021).

\subsection{The Implementation of Innovation-Driven Development Strategy Should Take the Path of Combining Independent, Cooperative and Asymmetric Innovation}

Autonomous innovation is the only road we can take and the wider we go, we 
must be determined to go on tenaciously. Only through independent innovation of core technologies can we truly use them for ourselves, grasp the pioneer and power source of development, have the initiative, and fundamentally guarantee the development of economy, military and society. We must not always lag behind others, following, waiting and expecting others to help, but only through self-improvement, self-reliance and self-transcendence can we lead the future. Autonomous innovation is also independent on the basis of cooperation, making full use of others' resources, absorbing and digesting others' excellent achievements, and promoting independent innovation from a higher starting point $(\mathrm{Li}$, 2022). While we adhere to the independent, cooperation, but also to take the "asymmetric" strategy, "better play their own advantages, in key areas, the neck of the place to make great efforts." We should focus our strengths, policies and resources around bottlenecks, build a solid foundation, cross cooperation, collaborative research and overall promotion (Zhao \& Wang, 2019).

\subsection{The Implementation of Innovation-Driven Development Strategy Should Let the Innovation Achievements "Go to the Sky" and "Enter the Ground"}

To make innovation achievements "up in the sky", there is a breakthrough (Zhu, 2019). The world is running hard on the runway of innovation, to refuel and run faster than others, to find more breakthroughs, to seize more opportunities, to improve the ability of research and follow-up, to improve the ability of digestion and absorption, to improve the ability of layout and planning, to improve the ability of teamwork and innovation, and to improve the ability to move from small breakthroughs to big breakthroughs. The only way to catch up or surpass is to accelerate, accelerate, and accelerate again, in order to have a bigger and better breakthrough.

To let the innovation results "into the ground", there is transformation (Zhu, 2019). Innovation achievements must be transformed in order to really realize the value of innovation; to really drive development, it must be transformed. Transformation to be evaluated by the market, to transform around the industrial chain, to better protect the property rights of innovation results, to improve the transformation of the law.

\section{Conclusion}

This paper summarizes the two connotations of innovation-driven development strategy: power and choice, and system engineering. Based on the literature research method, it summarizes the five implementation paths of innovation-driven development strategy: scientific and technological innovation, talent innovation, independent innovation, and transformation innovation. We have to mark new and different, and the key to shorten the gap between China and developed countries depends on innovation. We should pay attention to innovation infrastructure, platform construction, environment construction, policy construction and talent construction, and strive to improve the level of independent innova- 
tion in basic theory research, high-end practical research, frontier hotspot research, public interest research and social bottleneck research. Each of our innovation team and each of our innovation talents should treat learning and innovation as something to be done at all times, in everything and everywhere, integrate learning and innovation into work, study and life, love innovation and enjoy innovation, can often use the two connotations and four paths of innovation-driven development strategy to promote, enrich and test our innovation practice, so that we can better practice the innovation-driven development strategy. This paper is only a macroscopic study at present, and in the future, we will collect data related to the innovation-driven development strategy and conduct research on quantitative assessment.

\section{Acknowledgements}

1) Jiangsu Province Education Reform and Development Strategic and Policy Research Major Project: Jiangsu high-level teacher team construction research, Project No. 202000206.

2) Project of Jiangsu Provincial Education Department: Research on talent management innovation of universities based on big data in the context of "double first-class”, Project No. 72031941028A.

\section{Conflicts of Interest}

The author declares no conflicts of interest regarding the publication of this paper.

\section{References}

Li, B. (2021). Centennial Revival and the Formation of Scientist Spirit. Journal of the Chinese Academy of Sciences, No. 36, 692-697.

Li, L., \& Zhang, M. Y. (2020). The Historical Implications, Internal Logic and Contemporary Value of "Being Beaten if You Fall behind". Thought Education Research, No. 7, 131-135.

Li, Y. B. (2022). Qian Xuesen's Opinion on Independent Innovation of National Cutting-Edge Technology. Nature Dialectics Letters, No. 44, 83-91.

Shen, Z. X. (2021). The Evolution of the Chinese Communist Party's Thought on Science and Technology and Development Strategy in the Past Century. Research on Finance and Economics, No. 12, 12-20.

Shen, J. B. (2021). The "Four Comprehensives" Empower Chinese Modernization and High-Quality Development. School Party Construction and Thought Education, No. $19,22-24$.

Shi, H. B, \& Li, M. Q. (2021). Promoting the Chinese Spirit in Strengthening the Collective Memory of the Chinese Nation. Marxism and Reality, No. 6, 179-186.

Wang, H., \& Gu, J. M. (2019). Top Scientific and Technological Talents and Their Cultivation Mode under the Paradigm of Big Science-An Analysis Based on the Phenomenon of Japanese Nobel Prize Blowout in the 21st Century. Research on Higher Engineering Education, No. 3, 69-75.

Yin, D. S. (2021). The “Two Major Layouts” Promote a New Leap of Chinese Moderniza- 
tion Theory. Shanghai Economic Research, No. 12, 5-13.

Zhao, C., \& Wang, T. N. (2019). The Impact of Partner Age Asymmetry on the Value of a Firm's Strategic Alliance. Management Review, No. 31, 183-194.

Zhu, Y. X. (2019). Educational Scientific Research Should Be "up to the Sky" and "into the Ground". Education Research, No. 40, 21-22. 